\title{
Management of Thrombocytopenia in Chronic Liver Disease: Focus on Pharmacotherapeutic Strategies
}

\author{
Raoel Maan $^{1} \cdot$ Robert J. de Knegt ${ }^{1} \cdot$ Bart J. Veldt $^{1}$
}

Published online: 26 October 2015

(c) The Author(s) 2015. This article is published with open access at Springerlink.com

\begin{abstract}
Thrombocytopenia (platelet count $<150 \times 10^{9} / \mathrm{L}$ ) often complicates chronic liver disease, impeding optimal management of these patients. The prevalence of this manifestation ranges from $6 \%$ among non-cirrhotic patients with chronic liver disease to $70 \%$ among patients with liver cirrhosis. It has also been shown that the severity of liver disease is associated with both prevalence and level of thrombocytopenia. Its development is often multifactorial, although thrombopoietin is thought to be a major factor. The discovery of and ability to clone thrombopoietin led to new treatment opportunities for this clinical manifestation. This review discusses data on the three most important thrombopoietin receptor agonists: eltrombopag, avatrombopag, and romiplostim. Currently, only eltrombopag is approved for usage among patients with thrombocytopenia and chronic hepatitis $\mathrm{C}$ virus infection in order to initiate and maintain interferon-based antiviral treatment. Nevertheless, the optimal management of hematologic abnormalities among patients with chronic liver disease, and its risk for bleeding complications, is still a matter of discussion. Thrombocytopenia definitely contributes to hemostatic defects but is often counterbalanced by the enhanced presence of procoagulant factors. Therefore, a thorough assessment of the patient's risk for
\end{abstract}

Raoel Maan

r.maan@erasmusmc.nl

Robert J. de Knegt

r.deknegt@erasmusmc.nl

Bart J. Veldt

B.Veldt@rdgg.nl

1 Department of Gastroenterology and Hepatology, Erasmus MC University Medical Center Rotterdam, 's Gravendijkwal 230, Room Ha 206, 3015 CE Rotterdam, The Netherlands thrombotic events is essential when the use of thrombopoietin receptor agonists is considered among patients with chronic liver disease and thrombocytopenia.

\section{Key Points}

Thrombocytopenia in chronic liver disease is often multifactorial, with severity of liver disease the most influential factor.

Currently, only eltrombopag has been approved for use among patients with chronic hepatitis $\mathrm{C}$ virus infection to allow the initiation and maintenance of interferon-based therapy, but romiplostim and avatrombopag are also promising agents.

A thorough assessment of the patient's risk for thrombotic events is essential when the use of thrombopoietin receptor agonists is considered among patients with chronic liver disease and thrombocytopenia.

\section{Introduction}

Chronic liver disease is frequently complicated by thrombocytopenia (i.e., platelet count $<150 \times 10^{9} / \mathrm{L}$ ), which hampers the medical management of patients [1-5]. Diversity in cut-off values and patient populations means the prevalence of thrombocytopenia in different studies ranges from $6 \%$ among non-cirrhotic patients with chronic liver disease up to $70 \%$ among patients with liver cirrhosis [6]. Both prevalence and level of thrombocytopenia are associated with the severity of liver disease, as well as with long-term outcome of the disease [7-12]. The clinical 
significance of thrombocytopenia has been subject to intense discussion over recent years. Platelets do indeed have a critical role in normal hemostasis, hence thrombocytopenia influences coagulopathy in chronic liver disease [13-15]. However, a normal platelet number of $150-350 \times 10^{9} / \mathrm{L}$ far exceeds the number of platelets that is necessary for hemostasis, as major spontaneous bleeding will generally not occur until the platelet count is $<10 \times 10^{9} / \mathrm{L}[16]$.

Before the approval of eltrombopag by the US Food and Drug Administration (FDA) in 2008, and in Europe by the European Medicines Agency (EMA) in 2009, treatment options for clinically relevant thrombocytopenia consisted of platelet transfusion, splenic artery embolization, splenectomy, and transjugular intrahepatic portosystemic stent shunting. While these treatment options often effectively increased the platelet count, costs and risks were substantial. Platelet transfusion, the most effective option, can become refractory after multiple platelet transfusions due to human leukocyte antigen alloimmunization. Moreover, it is associated with the development of febrile nonhemolytic reactions and transfusion-related infections [1719]. The other more invasive methods of treating thrombocytopenia are also associated with substantial risks [2022]. Since 1994, when cloning of thrombopoietin became possible, several agents have been investigated for the pharmacological treatment of thrombocytopenia.

The current review focuses on the pathophysiology of thrombocytopenia, its impact on adequately treating the underlying disease, and the pharmacological treatment options for thrombocytopenia that are available or under investigation.

\section{The Life Cycle of Platelets}

Platelets are the smallest blood cells, as they consist of fragments of megakaryocyte cytoplasm. Megakaryocyte maturation involves nuclear duplication without cell division, resulting in very large cells. These megakaryocytes are located in the bone marrow, next to the sinusoidal walls, facilitating the exit of large fragments of cytoplasm into the circulation. Further fragmentation of megakaryocyte cytoplasm into individual platelets is the result of shear forces of the circulating blood [16].

There are several important regulators in the process of megakaryocytopoiesis, including interleukin (IL)-3, -6, and -11 and steel factor, among which thrombopoietin is the dominant hormone (Fig. 1) [23]. The term 'thrombopoietin' dates from 1958, when it was first used to describe the humoral basis of megakaryocyte and platelet production

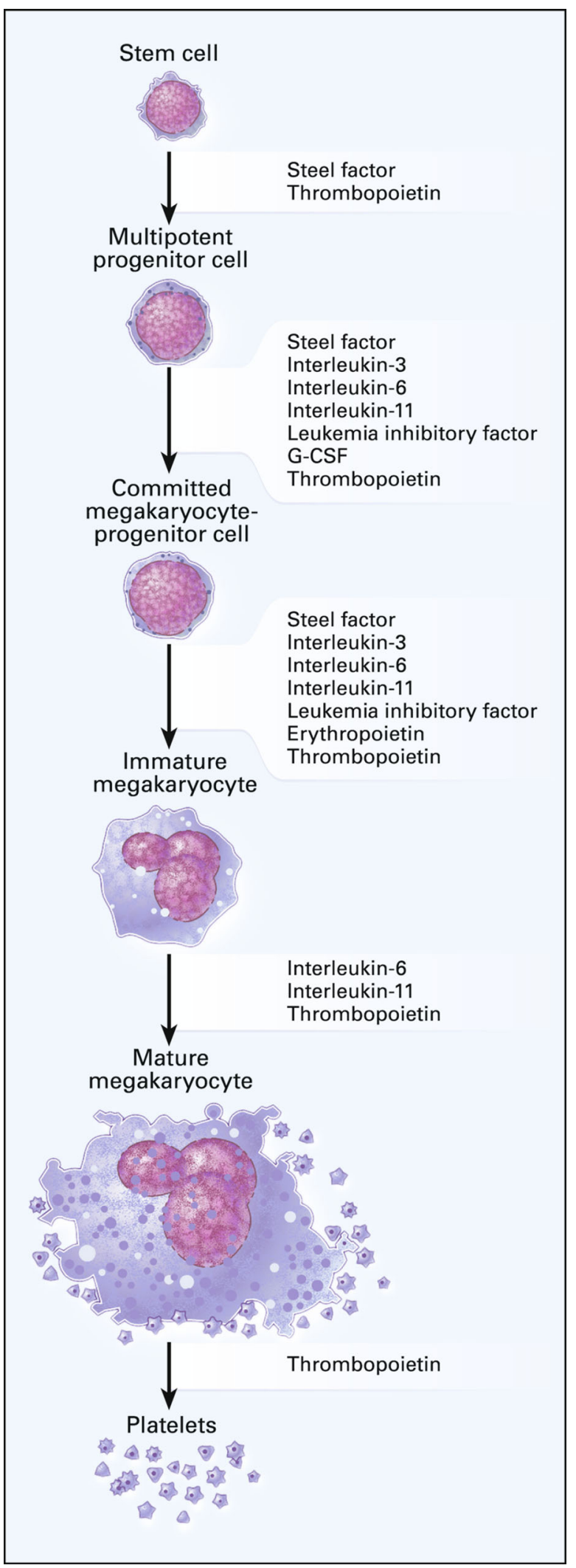

Fig. 1 The megakaryocytopoiesis process. G-CSF granulocyte-colony stimulating factor. With permission [23] 
[24]. However, the complete process was not understood until 1994, when cloning this main regulator of platelet production became possible [25-28]. By then, the cellular physiology had been understood for a decade. The protein of thrombopoietin consists of two domains, of which the amino-terminal shares great homology with erythropoietin and binds the c-MPL receptor on the surface of megakaryocytes and platelets. The carboxyl terminal is responsible for the circulatory half-life of the hormone as well as for aiding the folding of the polypeptide into the hormone [23].

Platelets have a lifespan in the circulation of around 10 days [29]. It is estimated that the spleen sequesters approximately one-third of the circulating platelets. This fraction increases when splenomegaly is present due to increased portal venous pressure, but platelet survival time remains unchanged in this situation [16]. Recently, it was found that the survival of platelets is regulated by apoptosis [30]. Mason et al. [30] showed that an intrinsic genetic program controls platelet survival and thereby dictates their lifespan. Only a small fraction of platelets is continually removed from the circulation due to its utilization in maintaining vascular integrity.

\section{Pathogenesis of Thrombocytopenia in Chronic Liver Disease}

The pathogenesis of thrombocytopenia in chronic liver disease is multifactorial, and different theories have been proposed. The pathogenesis may depend on the underlying etiology of the liver disease. The hypothesis of 'hypersplenic thrombocytopenia' dates from 1966, when Aster [31] described the pooling of platelets in the spleen in patients with liver cirrhosis. Cirrhosis is characterized by a complete distortion of hepatic architecture; it causes loss of liver cell function and impairment of liver circulation. This process leads to increased pressure in the portal veins, splenomegaly, and subsequent thrombocytopenia via the sequestration of platelets. However, thrombocytopenia may persist after treatments aimed to reverse portal hypertension [22, 32]. This suggests that mechanisms other than 'splenic pooling' should also be considered. A thorough evaluation of patients with thrombocytopenia and chronic liver disease is therefore warranted.

In addition to the sequestration of platelets, the pathogenesis of thrombocytopenia in chronic liver disease can be divided into two general points of action. The first is central and includes myelosuppression caused by the etiological factor or by the treatment thereof. The second is peripheral, involving autoantibodies against platelets.

The toxic effects of alcohol as well as viral-induced thrombocytopathy and bone marrow suppression are well known to cause thrombocytopenia [33, 34]. The exact mechanisms by which ethanol hampers normal hematopoiesis are still unclear. One hypothesis is that the cytopenia is due to polymorphisms in genes responsible for metabolism of alcohol-derived reactive aldehydes [35]. Among patients with chronic viral liver disease, the presence of immune complex-associated platelet clearance and reticuloendothelial destruction have also been described as inducing thrombocytopenia. Nagamine et al. [37] showed that, among $88 \%$ of patients with chronic hepatitis $\mathrm{C}$ virus (HCV) infection, elevated titers of platelet-associated immunoglobulin G (PAIgG) were present. It is thought that these immunoglobulins represent immune complex-coated platelets, and their levels gradually increase as the severity of liver disease increases. Moreover, the levels of PAIgG were inversely correlated with platelet count [36, 37].

Treatment-induced thrombocytopenia often complicates interferon-based antiviral treatment for chronic hepatitis B virus (HBV) or HCV infection [38-40]. Bone marrow suppression is thought to be the main mechanism in which interferon causes thrombocytopenia and neutropenia [39]. It has also been shown to inhibit progenitor cells of all hematological lineages. Peck-Radosavljevic et al. [41] found that, during interferon-based therapy, the thrombopoietin response is involved in the development of thrombocytopenia. They assessed thrombopoietin levels before and after interferon treatment in 30 patients without cirrhosis and 15 patients with cirrhosis. Median decrease in platelet count did not differ between these patients (35 and $32 \%$, respectively). The increase in thrombopoietin levels was relatively small for the decrease in platelet count among the patients without cirrhosis (median increase $43 \%$ ) and even decreased among cirrhotic patients (median decrease of $5 \%$ ). This blunted thrombopoietin response could contribute to the occurrence of thrombocytopenia during interferon-based therapy for chronic HCV infection [41]. Autoantibodies against platelet surface antigens are frequently found in patients with chronic liver disease. These autoantibodies can cause enhanced removal of platelets by the splenic and hepatic reticuloendothelial system. This leads to rapid destruction, which is also observed in chronic immune thrombocytopenic purpura (ITP) [42]. Kajihara et al. [43] examined anti-platelet autoimmunity in cirrhotic patients with thrombocytopenia by determining the autoantibody response to glycoprotein IIb-IIIa (GPIIb-IIIa) in vitro. This complex is the most important platelet surface autoantigen recognized by anti-platelet antibodies among patients with chronic ITP. By stimulating cultures of peripheral blood mononuclear cells (PBMCs) with GPIIb-IIIa, the anti-GPIIb-IIIa antibody production was assessed in 72 patients with liver cirrhosis, 62 patients with ITP, and 52 healthy controls. The frequency of anti- 
GPIIb-IIIa antibody-producing B cells in patients with liver cirrhosis was significantly greater than in the healthy controls $\quad\left(10.9 \pm 6.2\right.$ vs. $0.4 \pm 0.3 / 10^{5} \quad$ PBMCs, $p<0.001)$. Even compared with patients with ITP, this frequency was higher among patients with liver cirrhosis $(8.2 \pm 5.2$ for ITP patients, $p=0.007)$. This study suggested that platelet destruction induced by autoantibodies may partly contribute to the occurrence of thrombocytopenia in this specific population [43]. Another interesting study assessed platelet production and destruction among patients with liver cirrhosis. Of the 91 consecutive patients with liver cirrhosis included in this study, 36 had HCV-induced cirrhosis, 40 had alcoholic cirrhosis, and 15 had HBV-induced cirrhosis. Subjects with ITP (25) or aplastic anemia (10) and healthy blood donors (40) were included as controls. Patients with liver cirrhosis had significantly lower levels of thrombopoietin $(29.9 \pm 18.1 \mathrm{\rho g} / \mathrm{ml})$ than did controls $(82.3 \pm 47.6 \mathrm{\rho g} /$ $\mathrm{ml}$ ) with no difference on the basis of the etiology. In contrast, thrombopoietin levels were above normal among patients with ITP $(155 \pm 76 \mathrm{\rho g} / \mathrm{ml})$ or aplastic anemia $(508 \pm 86.1 \mathrm{\rho g} / \mathrm{ml})$. Absolute levels of reticulated platelets were lower in patients with liver cirrhosis than in healthy controls. As a measure of platelet destruction, plasma glycocalicin was also assessed. The glycocalicin index was within normal limits among the healthy subjects $(0.9 \pm 0.2)$, while significantly higher among patients with $\mathrm{HCV}$-induced cirrhosis $(1.96 \pm 1.40)$, alcoholic cirrhosis $(1.79 \pm 1.51)$, or HBV-induced cirrhosis $(1.71 \pm 1.69)(p<0.006$ for all). Moreover, serum anti-platelet antibodies were higher among patients with $\mathrm{HCV}$-induced liver cirrhosis than among healthy subjects $(p<0.006)$ and those with alcoholic liver cirrhosis $(p<0.018)$ or HBV-induced liver cirrhosis $(p<0.001)$. This study thus showed that patients with liver cirrhosis have decreased plasma thrombopoietin levels, higher platelet turnover, and reduced platelet production. Moreover, HCV-induced liver cirrhosis was associated with higher levels of serum anti-platelet antibodies [44]. Olariu et al. [45] evaluated several possible causes for thrombocytopenia among 81 patients without cirrhosis. They divided their study population into three groups according to platelet count and performed a bone marrow biopsy and assessed anti-platelet antibodies in all patients. They found that both central and peripheral causes of thrombocytopenia were present in patients with a platelet count $<100 \times 10^{9} / \mathrm{L}$, whereas the presence of anti-platelet antibodies alone was more prevalent among patients with a platelet count between $126 \times 10^{9} / \mathrm{L}$ and $149 \times 10^{9} / \mathrm{L}$ [45]. Although there were some limitations to these studies, they underline the multifactorial etiology of thrombocytopenia in chronic liver disease.

\section{Impact of Thrombocytopenia on Treating the Underlying Disease or before Interventions}

Thrombocytopenia frequently complicates the management of patients with chronic liver disease who require treatment for their underlying disease or before undergoing invasive procedures. The two most important clinical situations in which thrombocytopenia may hamper the management of these patients are described below.

\subsection{Limiting Antiviral Therapy for Chronic HCV Infection}

Chronic HCV infection is a leading cause for end-stage liver disease and liver transplantation in Europe and the USA [46]. To prevent progression towards decompensated liver cirrhosis, patients with HCV are treated with antiviral treatment aimed at reaching a sustained virological response (SVR), i.e., absence of HCV RNA in the serum at 6 months after the end of treatment. Indeed, it has been shown that successful antiviral treatment, leading to SVR, is associated with a reduced risk of liver failure and liver transplantation [12, 47]. Until 2013, all treatment regimens included pegylated interferon alpha (PegIFN). However, treatment with PegIFN is problematic in patients with liver cirrhosis, since one of its many side effects is thrombocytopenia. Thus, thrombocytopenia is likely to worsen during antiviral treatment with PegIFN and therefore, severe thrombocytopenia has generally been regarded as a contraindication for PegIFN treatment.

A recent European retrospective multicenter study including 466 patients with platelets $<100 \times 10^{9} / \mathrm{L}$ showed that 184 of 466 patients $(39.5 \%)$ did not receive IFN-based therapy during the study period. Treatment was most frequently withheld due to multiple clinical characteristics, including hepatic cirrhosis (16.3\%), thrombocytopenia $(16.3 \%)$, and age $>60$ years $(10.9 \%)$. Overall, thrombocytopenia was reported as the only reason for withholding treatment in $4.9 \%$ of untreated patients in this study [3]. These figures are in line with the findings of Giannini et al. [2], who evaluated 1538 patients with chronic HCV who were referred between June 2002 and May 2011 and potentially eligible for antiviral treatment. They found that thrombocytopenia limited treatment initiation in $6.5 \%$ of patients [2]. A large American study evaluated potential contraindications for antiviral therapy in a dataset of 45,690 patients with HCV [48]. Thrombocytopenia was mentioned as a potential contraindication in $1.1 \%$ of the patients, using a lower cut-off $\left(50 \times 10^{9} / \mathrm{L}\right)$ than the two studies mentioned above.

In clinical practice, clinicians have been treating patients with HCV-induced thrombocytopenia in whom they 
thought the risk of bleeding complications during treatment would outweigh the risks associated with disease progression of untreated ongoing $\mathrm{HCV}$ infection. To assess the risks and benefits of PegIFN-based treatment in patients with HCV with thrombocytopenia, Maan et al. [49] retrospectively investigated 546 patients who were consecutively treated in five large hepatology units in Europe and Canada between 1990 and 2003. Overall, 859 treatments were administered to 546 patients: in $38 \%$ of the treatments, patients had moderate baseline thrombocytopenia with platelets between 75 and $150 \times 10^{9} / \mathrm{L}$, and in $6 \%$ of the treatments, patients had severe baseline thrombocytopenia with platelets $<75 \times 10^{9} / \mathrm{L}$ [49]. In this study, bleeding complications were more common in patients with platelet counts $<50 \times 10^{9} / \mathrm{L}$, but were generally mild. A total of 18 patients with severe thrombocytopenia reported a bleeding complication: seven had epistaxis, two had gingival bleeding, six had hematuria, two had rectal blood loss, and one had a subconjunctival hemorrhage. Overall, two major bleeding episodes occurred. Both were variceal bleeding episodes that occurred in patients with moderate baseline thrombocytopenia, but which were likely related to the underlying liver disease and portal hypertension and not directly to the thrombocytopenia. Although thrombocytopenia was independently associated with a reduced chance of achieving SVR, once achieved, SVR was associated with a marked reduction in cirrhosisrelated morbidity and mortality, especially in patients with baseline thrombocytopenia.

Since the introduction of PegIFN-free direct-acting antiviral treatment regimens, thrombocytopenia does not seem to be a contraindication to HCV therapy [50]. In a recent study including $61 \mathrm{HCV}$ patients who were treated with a combination of sofosbuvir and ribavirin (RBV) while on the waiting list for liver transplantation, platelet counts increased during treatment from a baseline mean of $107 \times 10^{9} / \mathrm{L}$ to $120 \times 10^{9} / \mathrm{L}$ at week 24 [51].

\subsection{Limiting or Postponing Invasive Procedures}

Patients with chronic liver disease often need invasive procedures for diagnosis or therapy. The presence of thrombocytopenia can complicate this routine care, leading to delayed or cancelled invasive procedures. Currently, there are no globally accepted clinical guidelines for applying platelet transfusions when these patients undergo invasive procedures. In general, platelet counts of $\geq 80 \times 10^{9} / \mathrm{L}$ are often required for physicians in order to perform a percutaneous liver biopsy. However, some physicians consider a platelet count $\geq 50 \times 10^{9} / \mathrm{L}$ safe as it seemed that laparoscopic and transjugular liver biopsies could be safely performed when platelet count is $>50 \times 10^{9} / \mathrm{L}[52,53]$. A post hoc analysis from the
Hepatitis C Antiviral Long-Term Treatment against Cirrhosis (HALT-C) trial assessed 2740 liver biopsies that were performed in patients with bridging fibrosis and cirrhosis due to chronic HCV infection. Only 29 serious adverse events $(1.1 \%)$ were reported, of which bleeding was the most common (16 cases; $0.6 \%$ ). The bleeding rate was higher among patients with platelet counts $<60 \times 10^{9}$ / L [54]. Giannini et al. [55] assessed the incidence of bleeding following invasive procedures among 121 consecutive patients who were being evaluated for liver transplantation. In total, 50 (49\%) patients underwent an invasive procedure; 32 (64\%) of them had severe thrombocytopenia, which, in this study, was defined as a platelet count $<75 \times 10^{9} / \mathrm{L}$. Ten $(20 \%)$ patients who underwent an invasive procedure experienced a bleeding episode, and all had severe thrombocytopenia [55]. Sharma et al. [56] performed a study among 88 consecutive patients with end-stage liver disease who needed to undergo left-sided cardiac catheterization and were matched to 81 patients without known liver disease. The procedures were more complicated among the patients with liver failure, resulting in pseudoaneurysms in $5.7 \%(5 / 88)$ of the patients compared with $0 \%$ in the control group $(p=0.029)$. Moreover, major bleeding was higher in the group with liver disease than in the control group (14.8 vs. $3.7 \%, p=0.014$ ), causing a higher need for blood transfusion. Patients with liver failure also had a greater need for platelet transfusions (48.3 vs. $1.2 \%, p<0.001)$. Thrombocytopenia did not seem to be associated with the risk for complications, in contrast to pre- and post-procedural international normalized ratio (INR) [56].

A recent retrospective cohort study assessed the bleeding risk and management of bleeding in thrombocytopenic patients undergoing dental extraction. A total of 68 patients with hematologic disease and subsequent thrombocytopenia (platelet count $\leq 100 \times 10^{9} / \mathrm{L}$ ) underwent extraction of 200 teeth. Five $(7.4 \%)$ patients had postoperative bleeding that could be controlled with routine care and was more frequent with lower platelet levels $(\mathrm{p}=0.048) ; 32$ patients received platelet transfusion and 26 received local measures, but these interventions had no effect on bleeding outcomes [57].

\section{Therapeutic Options for Thrombocytopenia in Chronic Liver Disease}

Since its cloning, thrombopoietin and its receptor have been the main focus for the development of pharmacological treatment options of thrombocytopenia. Firstgeneration therapeutic thrombopoietin receptor agonists, among which recombinant human thrombopoietin (rhTPO) and pegylated human recombinant megakaryocyte growth 
and development factor (Peg-rHuMGDF) have been demonstrated as highly effective, have never been approved. The development of these agents ended when neutralizing autoantibodies were found to form, showing a cross-reaction with endogenous thrombopoietin, which sometimes even led to thrombocytopenia in healthy individuals [58-61]. Because these agents did demonstrate a clinical benefit, the development of thrombopoietic growth factors with the potential to stimulate platelet production but no antigenic effect was warranted. It was not until the early 2000s that thrombopoietic agents that specifically did not have any homology to endogenous thrombopoietin were developed. These agents are c-MPL receptor agonists and successfully enhance platelet production. Most of these agents are primarily developed for treating chronic ITP, and data on their application in thrombocytopenia in chronic liver disease are limited (Table 1).

\subsection{Eltrombopag}

Eltrombopag (Revolade ${ }^{\circledR}$; $\operatorname{Promacta}^{\circledR}$; GlaxoSmithKline Inc, Philadelphia, PA, USA) is an orally available, nonpeptide acting as a thrombopoietin receptor agonist. The drug interacts with the transmembrane domain of the thrombopoietin receptor on megakaryocyte precursors and megakaryocytes and induces their proliferation and differentiation in order to increase platelet production. After the preclinical and early clinical studies, eltrombopag was subject to one phase II trial and three phase III trials, which are described below. Three of these trials only included patients with chronic HCV infection, whereas the other trial included patients with cirrhosis of any origin. Recently, this journal published an excellent and detailed review on eltrombopag [62].

The first phase II trial dates from 2007, when McHutchison et al. [63] assessed whether the use of eltrombopag could increase platelet counts in patients with thrombocytopenia associated with cirrhosis due to chronic $\mathrm{HCV}$ infection in order to be able to initiate and maintain antiviral treatment with PegIFN and RBV. In total, 74 patients with HCV-related cirrhosis and a platelet count of $20-70 \times 10^{9} / \mathrm{L}$ were included and were treated for 4 weeks with placebo or eltrombopag $(30,50$, or $75 \mathrm{mg}$ daily). During the 4-week initiation phase, platelet counts increased in a dose-dependent manner $(p<0.001$ for overall treatment effect). Antiviral treatment could be initiated in 71-91\% of patients who were treated with eltrombopag, and the use of eltrombopag was continued during this treatment phase. In total, 36-65\% of the patients completed 12 weeks of antiviral treatment, with $65 \%$ of those receiving eltrombopag $75 \mathrm{mg}$. The most common side effects reported in this trial were headache, dry mouth, abdominal pain, and nausea. Furthermore, seven serious adverse events occurred, including ascites, retinal exudates, and myositis [63]. Due to these promising results, three phase III trials were conducted. The Eltrombopag Evaluated for Its Ability to Overcome Thrombocytopenia and Enable Procedures (ELEVATE) study randomly assigned 292 patients with chronic liver disease of diverse causes, all of whom had a platelet count of $<50 \times 10^{9} / \mathrm{L}$. Patients received a daily dose of eltrombopag $75 \mathrm{mg}$ or placebo for 14 days before an elective invasive procedure, which was performed within 5 days of the last dose. A platelet transfusion was avoided in 104 (72\%) of the 145 patients who received eltrombopag, whereas transfusion was avoided in $28(19 \%)$ of 147 patients receiving placebo $(p<0.001)$. There were no significant differences in bleeding episodes. The most common side effects reported in this study (in $>5 \%$ of patients) were headache, pyrexia, abdominal pain, diarrhea, nausea, and hepatic encephalopathy. A thrombotic event of the portal venous system was observed in six patients receiving eltrombopag and one patient receiving placebo. Five of the six patients had their event while the platelet count was $\geq 200 \times 10^{9} / \mathrm{L}$. This resulted in early termination of the study [64].

Two pivotal, multicenter, randomized phase III trials, Eltrombopag to Initiate and Maintain Interferon Antiviral Treatment to Benefit Subjects with Hepatitic C-Related Liver Disease (ENABLE)-1 and ENABLE-2, assessed the ability of eltrombopag to increase the platelet count and thereby enable subjects to initiate and maintain antiviral treatment with PegIFN and RBV. Both trials had an initiation phase using eltrombopag to increase platelet count above the threshold for treatment initiation (ENABLE-1: $90 \times 109 / \mathrm{L}$, using PegIFN-2a; and ENABLE-2: $100 \times 109 / \mathrm{L}$, using PegIFN-2b). Afterwards, patients were randomized to eltrombopag or placebo for the whole course of antiviral treatment. These trials included patients with chronic HCV infection and a platelet count $<75 \times 10^{9} / \mathrm{L}$; ENABLE-1 included 715 patients and ENABLE-2 included 805 patients. The threshold for treatment initiation was reached in $95 \%$ and $94 \%$ of patients in ENABLE-1 and 2, respectively. In both trials, more patients who received eltrombopag than placebo achieved SVR. In ENABLE-1, $23 \%$ of patients treated with eltrombopag attained SVR versus $14 \%$ in the placebo group ( $p=0.0064)$, and $19 \%$ of patients treated with eltrombopag versus $13 \%$ among those treated with placebo attained SVR in ENABLE-2 ( $p=0.0202)$. Regarding side effects, the safety of eltrombopag remained an important issue, as the rates of hepatic decompensation (10\% with eltrombopag vs. $5 \%$ with placebo) and thromboembolic events (3\% with eltrombopag and $1 \%$ with placebo) were higher in the group receiving eltrombopag [65]. Participants are currently being recruited for 


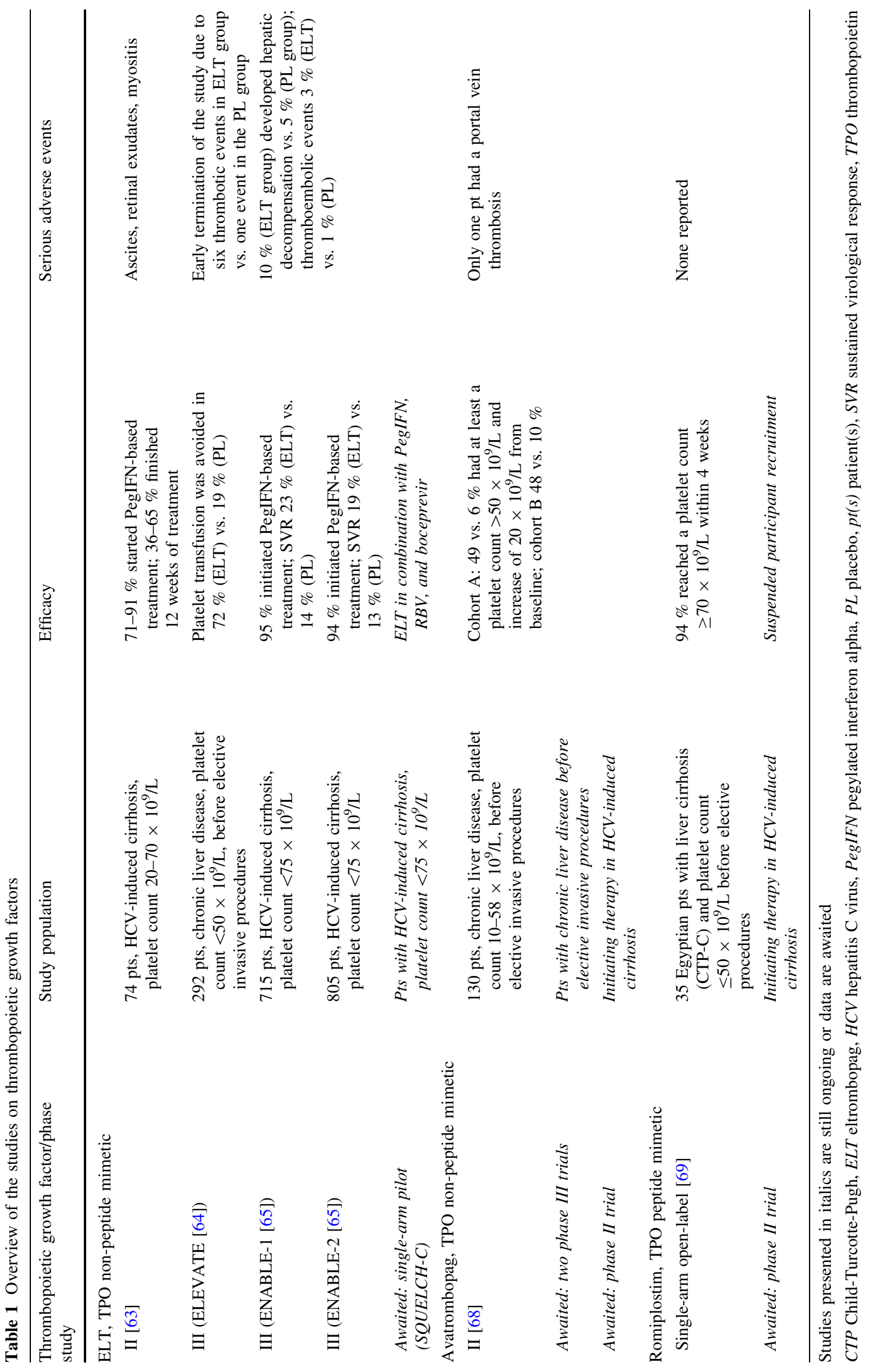


enrolment in SQUELCH-C, an investigator-initiated, single-arm, non-blinded pilot study on the use of eltrombopag in combination with PegIFN, RBV and boceprevir, for patients who would not otherwise be treatment candidates because of low platelet counts $\left(<75 \times 10^{9} / \mathrm{L}\right)$ (Clinical trial no: NCT01821625).

\subsection{Avatrombopag}

Avatrombopag (E5501, formerly YM477 and AKR-501; Eisai Inc, Woodcliff Lake, NJ, USA) is an orally administered, small-molecule thrombopoietin receptor agonist that has been shown to act like thrombopoietin in vitro and in vivo $[66,67]$. Like eltrombopag, it binds the thrombopoietin receptor and induces a cascade of cellular reactions that eventually leads to enhancement of megakaryocytic proliferation and differentiation and thereby the production of platelets. To date, one phase II multicentre study has been published, in which the efficacy and safety of avatrombopag was assessed among patients with cirrhosis and thrombocytopenia $\left(10-58 \times 10^{9} / \mathrm{L}\right)$ who had to undergo elective procedures. This study included 130 patients who were randomized to cohort A (67 patients) or cohort B (63 patients). In cohort A, patients were treated with placebo or three different doses of a firstgeneration avatrombopag formulation (100 mg loading dose followed by 20,40 , or $80 \mathrm{mg} /$ day on days $2-7$ ). Patients in cohort B were treated with placebo or a secondgeneration avatrombopag formulation $(80 \mathrm{mg}$ loading dose, followed by $10 \mathrm{mg} /$ day for days $2-7$, or $20 \mathrm{mg} /$ day for days 2-4). Phase I studies showed that the secondgeneration formulation produced about 1.6 times the exposure compared with the first-generation formulation $[66,67]$. In the treated group, $49 \%$ of patients in cohort A (vs. $6 \%$ among controls, $p<0.001$ ) achieved an increase in platelet count of at least $\geq 20 \times 10^{9} / \mathrm{L}$ compared with baseline and a platelet count of $>50 \times 10^{9} / \mathrm{L}$ at least once during days $4-8$. In cohort $\mathrm{B}, 48 \%$ of the treated patients achieved this primary endpoint compared with $10 \%$ of patients receiving placebo $(p=0.009)$. Platelet count increased in a dose-dependent manner among the patients treated with avatrombopag. As data were emerging regarding the association between these agents and portal vein thrombosis (PVT), a baseline Doppler ultrasound was included before cohort B was enrolled. In general, avatrombopag was well tolerated; nausea, fatigue, and headache were most commonly reported. Two patients achieved a platelet count $>200 \times 10^{9} / \mathrm{L}$ and neither of them developed a PVT. Only one patient, who was treated in cohort A with 100/80 mg, developed a PVT in this study. The patient had a Child-Turcotte-Pugh score of 10 (CTP C) and a model for end-stage liver disease (MELD) score of 19, indicating severe liver disease. Moreover, a prior ultrasound demonstrated low portal vein flow $(\sim 5 \mathrm{~cm} / \mathrm{s})$, probably increasing the risk of developing a PVT [68]. Currently, two global phase III trials are ongoing evaluating the efficacy and safety of once-daily oral avatrombopag for the treatment of adults with thrombocytopenia associated with liver disease prior to an elective procedure (Clinical trial no: NCT01972529 and NCT01976104). Furthermore, data are awaited from a phase II study evaluating the efficacy, safety, and pharmacokinetics of E5501 in subjects with chronic HCV-related thrombocytopenia who are potential candidates for antiviral treatment (Clinical trial no: NCT01355289).

\subsection{Romiplostim}

Romiplostim (Nplate ${ }^{\mathrm{TM}}$; Amgen Inc., Thousand Oaks, CA, USA) is another thrombopoietin receptor agonist that has four identical thrombopoietin agonist peptides and glycine bridges to connect these peptides. It also contains an $\mathrm{Fc}$ carrier domain to increase its half-life. The peptide has no sequence homology to endogenous thrombopoietin to avoid cross-reactive antibodies. Its mechanism of action is thought to be similar to that of thrombopoietin, directly binding to the thrombopoietin receptor and thereby initiating the signaling pathways. Recently, a single-center, single-arm, open-label study was conducted investigating the effect of preoperative romiplostim treatment among 35 Egyptian patients with chronic HCV infection, liver cirrhosis (CTP C), and subsequent thrombocytopenia $\left(\leq 50 \times 10^{9} / \mathrm{L}\right)$. Patients had not responded to standard treatment and were treated with a weekly subcutaneous injection at a fixed dose of $2 \mu \mathrm{g} / \mathrm{kg}$. They were treated for a maximum of 4 weeks or until two consecutive visits with a platelet count of $\geq 70 \times 10^{9} / \mathrm{L}$. In total, $33(94 \%)$ of the 35 patients achieved the primary endpoint of two consecutive visits with a platelet count $\geq 70 \times 10^{9} / \mathrm{L}$. Most of the patients reached this target between day 12 and day 18 . The two patients who did not reach this level achieved platelet counts of 48 and $61 \times 10^{9} /$ L. Surprisingly, no serious adverse events were observed during the treatment period. None of the subjects experienced a postoperative bleeding episode, and none of them experienced a thromboembolic event 60 days after the procedure. Some patients experienced some degree of headache on the day of the injection, but no other side effects were reported [69]. A phase II trial assessing the efficacy and safety of romiplostim administered to thrombocytopenic patients with chronic $\mathrm{HCV}$ infection who are not candidates for antiviral treatment with PegIFN and RBV due to persistent thrombocytopenia has currently suspended participant recruitment and an interim analysis is awaited (Clinical trial no: NCT01153919). So far, three case reports describing four patients with chronic HCV infection (one had HIV/HCV coinfection) have shown that romiplostim was able to initiate or 
maintain antiviral therapy with PegIFN and RBV and thereby these patients were able to achieve an SVR [70-72]. Another case report described a patient with $\mathrm{HCV}$-induced cirrhosis who had to undergo treatment for a hepatoma. Treatment was withheld because of thrombocytopenia, and after starting romiplostim the patient was successfully treated [73]. A final case report again stresses the importance of appropriate patient selection and close monitoring while patients are receiving thrombopoietin receptor agonists. Dultz et al. [74] described a cirrhotic patient with chronic $\mathrm{HCV}$ infection who was treated for thrombocytopenia with romiplostim for 9 months. She was found to have a PVT, and the platelet count was $>330 \times 10^{9} / \mathrm{L}$.

\section{Conclusion}

Thrombocytopenia is a common manifestation among patients with chronic liver disease and could be considered as an important parameter for defining the severity of the liver disease. The pathogenesis of thrombocytopenia is often multifactorial, with thrombopoietin being essential in the current development of pharmacotherapeutic agents. So far, only eltrombopag has been approved for usage among patients with chronic $\mathrm{HCV}$ infection to allow the initiation and maintenance of IFN-based therapy [75, 76]. Romiplostim has been approved for the treatment of thrombocytopenia in patients with chronic ITP who have insufficient response to corticosteroids, immunoglobulins, or splenectomy. However, its usage is not approved in chronic liver disease [77, 78]. Avatrombopag is a promising agent that could probably be used for thrombocytopenic patients with chronic liver disease undergoing elective procedures. As data comparing one thrombopoietin agonist with another are lacking, it is hard to recommend its usage in the management of thrombocytopenia among patients with chronic liver disease. The use of eltrombopag (and romiplostim when approved in chronic liver disease) should be limited to those patients who require chronic thrombopoietin stimulation, like patients undergoing PegIFN-based antiviral therapy for chronic HCV infection. However, its use among these patients is a major concern. The risk of hepatic decompensation is considerably increased when patients with severe thrombocytopenia are allowed to undergo PegIFN-based antiviral treatment. Recently, the discovery of direct-acting antivirals has revolutionized treatment for patients with chronic HCV infection. It could therefore be questioned whether patients with chronic HCV infection and thrombocytopenia still necessitate thrombopoietin receptor agonists, as most regimens have abandoned the usage of PegIFN or shortened its usage to 12 weeks [79-81]. When a temporary increase in platelet count is needed, avatrombopag should be considered, since most data on the use of avatrombopag are among patients with liver cirrhosis undergoing elective procedures. Whether there is an optimal platelet count that should be attained after initiation of a thrombopoietin agonist is currently unclear, but it very much depends on the indication for its use. Before considering prescribing a thrombopoietin agonist, physicians must perform extensive evaluation of a patient's risk of thrombotic events. This evaluation includes the assessment of the presence of patent hepatic vessels and flow in the portal vein. Once thrombopoietin agonists are being used, patients should be closely monitored by Doppler sonography as well as for abdominal complaints. As one of the studies on eltrombopag suggested an association between platelet count $>200 \times 10^{9} / \mathrm{L}$ and the occurrence of PVT events, termination of thrombopoietin agonists should be considered when this threshold has been exceeded [64].

The optimal management of hematologic abnormalities among patients with chronic liver disease and its risk for bleeding complications is still a matter of discussion. The balance in the hemostatic system among patients with chronic liver disease, including coagulation, platelets, and fibrinolysis, has been extensively described elsewhere [14]. Thrombocytopenia definitely contributes to hemostatic defects but is often counterbalanced by the enhanced presence of procoagulant factors. Therefore, a thorough assessment of the patient's risk for thrombotic events is essential when the use of thrombopoietin receptor agonists is considered among patients with chronic liver disease and thrombocytopenia.

\section{Compliance with Ethical Standards}

R. Maan has received financial compensation for consultancy from AbbVie. R. J. de Knegt reports that his institution has received financial compensation for consultancy activities and/or lecture activities from Merck, Janssen, Roche, Gilead, and Medtronic, and research grants from Merck, GlaxoSmithKline, and Roche. B. J. Veldt has received financial compensation for board membership at GlaxoSmithKline and Janssen Therapeutics.

No funding was received for the preparation of this manuscript.

Open Access This article is distributed under the terms of the Creative Commons Attribution-NonCommercial 4.0 International License (http://creativecommons.org/licenses/by-nc/4.0/), which permits any noncommercial use, distribution, and reproduction in any medium, provided you give appropriate credit to the original author(s) and the source, provide a link to the Creative Commons license, and indicate if changes were made.

\section{References}

1. Afdhal N, McHutchison J, Brown R, Jacobson I, Manns M, Poordad F, et al. Thrombocytopenia associated with chronic liver disease. J Hepatol. 2008;48(6):1000-7. 
2. Giannini EG, Marenco S, Fazio V, Pieri G, Savarino V, Picciotto A. Peripheral blood cytopaenia limiting initiation of treatment in chronic hepatitis $\mathrm{C}$ patients otherwise eligible for antiviral therapy. Liver Int. 2012;32(7):1113-9.

3. Rizzetto M, Grotzinger K, Theodore D, Demuth D, Irving WL, Manns $\mathrm{M}$, et al. Reasons for nonuse of antiviral treatment in patients with chronic hepatitis $\mathrm{C}$ infection and thrombocytopaenia: a retrospective chart review from five European countries. J Viral Hepat. 2014;21(10):e129-34.

4. Rockey DC, Caldwell SH, Goodman ZD, Nelson RC, Smith AD, American Association for the Study of Liver Disease. Liver biopsy. Hepatology. 2009;49(3):1017-44.

5. Slichter SJ. Relationship between platelet count and bleeding risk in thrombocytopenic patients. Transfus Med Rev. 2004;18(3): 153-67.

6. Giannini EG. Review article: thrombocytopenia in chronic liver disease and pharmacologic treatment options. Aliment Pharmacol Ther. 2006;23(8):1055-65.

7. Giannini E, Botta F, Borro P, Risso D, Romagnoli P, Fasoli A, et al. Platelet count/spleen diameter ratio: proposal and validation of a non-invasive parameter to predict the presence of oesophageal varices in patients with liver cirrhosis. Gut. 2003;52(8):1200-5.

8. Lu SN, Wang JH, Liu SL, Hung CH, Chen CH, Tung HD, et al. Thrombocytopenia as a surrogate for cirrhosis and a marker for the identification of patients at high-risk for hepatocellular carcinoma. Cancer. 2006;107(9):2212-22.

9. Cardoso AC, Moucari R, Figueiredo-Mendes C, Ripault MP, Giuily N, Castelnau C, et al. Impact of peginterferon and ribavirin therapy on hepatocellular carcinoma: incidence and survival in hepatitis $\mathrm{C}$ patients with advanced fibrosis. J Hepatol. 2010;52(5):652-7.

10. Fattovich G, Giustina G, Degos F, Diodati G, Tremolada F, Nevens F, et al. Effectiveness of interferon alfa on incidence of hepatocellular carcinoma and decompensation in cirrhosis type $\mathrm{C}$. European Concerted Action on Viral Hepatitis (EUROHEP). J Hepatol. 1997;27(1):201-5.

11. Morgan TR, Ghany MG, Kim HY, Snow KK, Shiffman ML, De Santo JL, et al. Outcome of sustained virological responders with histologically advanced chronic hepatitis C. Hepatology. 2010;52(3):833-44.

12. van der Meer AJ, Veldt BJ, Feld JJ, Wedemeyer H, Dufour JF, Lammert $\mathrm{F}$, et al. Association between sustained virological response and all-cause mortality among patients with chronic hepatitis $\mathrm{C}$ and advanced hepatic fibrosis. JAMA. 2012;308(24):2584-93.

13. Tripodi A, Mannucci PM. Abnormalities of hemostasis in chronic liver disease: reappraisal of their clinical significance and need for clinical and laboratory research. J Hepatol. 2007;46(4):727-33.

14. Tripodi A, Mannucci PM. The coagulopathy of chronic liver disease. N Engl J Med. 2011;365(2):147-56.

15. Violi F, Basili S, Raparelli V, Chowdary P, Gatt A, Burroughs AK. Patients with liver cirrhosis suffer from primary haemostatic defects? Fact or fiction? J Hepatol. 2011;55(6):1415-27.

16. George JN. Platelets. Lancet. 2000;355(9214):1531-9.

17. Demetri GD. Targeted approaches for the treatment of thrombocytopenia. Oncologist. 2001;6(Suppl 5):15-23.

18. McCullough J. Current issues with platelet transfusion in patients with cancer. Semin Hematol. 2000;37(2 Suppl 4):3-10.

19. Perrotta PL, Snyder EL. Non-infectious complications of transfusion therapy. Blood Rev. 2001;15(2):69-83.

20. Hadduck TA, McWilliams JP. Partial splenic artery embolization in cirrhotic patients. World J Radiol. 2014;6(5):160-8.

21. Rodeghiero F, Ruggeri M. Short- and long-term risks of splenectomy for benign haematological disorders: should we revisit the indications? Br J Haematol. 2012;158(1):16-29.
22. Wong F. The use of TIPS in chronic liver disease. Ann Hepatol. 2006;5(1):5-15.

23. Kaushansky K. Thrombopoietin. N Engl J Med. 1998;339(11):746-54. doi:10.1056/NEJM199809103391107.

24. Kelemen E, Cserhati I, Tanos B. Demonstration and some properties of human thrombopoietin in thrombocythaemic sera. Acta Haematol. 1958;20(6):350-5.

25. Bartley TD, Bogenberger J, Hunt P, Li YS, Lu HS, Martin F, et al. Identification and cloning of a megakaryocyte growth and development factor that is a ligand for the cytokine receptor Mpl. Cell. 1994;77(7):1117-24.

26. de Sauvage FJ, Hass PE, Spencer SD, Malloy BE, Gurney AL, Spencer SA, et al. Stimulation of megakaryocytopoiesis and thrombopoiesis by the c-Mpl ligand. Nature. 1994;369(6481):533-8.

27. Lok S, Kaushansky K, Holly RD, Kuijper JL, Lofton-Day CE, Oort PJ, et al. Cloning and expression of murine thrombopoietin cDNA and stimulation of platelet production in vivo. Nature. 1994:369(6481):565-8.

28. Sohma Y, Akahori H, Seki N, Hori T, Ogami K, Kato T, et al. Molecular cloning and chromosomal localization of the human thrombopoietin gene. FEBS Lett. 1994;353(1):57-61.

29. Leeksma $\mathrm{CH}$, Cohen JA. Determination of the life of human blood platelets using labelled diisopropylfluorophosphanate. Nature. 1955;175(4456):552-3.

30. Mason KD, Carpinelli MR, Fletcher JI, Collinge JE, Hilton AA, Ellis S, et al. Programmed anuclear cell death delimits platelet life span. Cell. 2007;128(6):1173-86.

31. Aster RH. Pooling of platelets in the spleen: role in the pathogenesis of "hypersplenic" thrombocytopenia. J Clin Invest. 1966;45(5):645-57.

32. Jabbour N, Zajko A, Orons P, Irish W, Fung JJ, Selby RR. Does transjugular intrahepatic portosystemic shunt (TIPS) resolve thrombocytopenia associated with cirrhosis? Dig Dis Sci. 1998;43(11):2459-62.

33. Ballard HS. Hematological complications of alcoholism. Alcohol Clin Exp Res. 1989;13(5):706-20.

34. Peck-Radosavljevic M. Thrombocytopenia in liver disease. Can J Gastroenterol. 2000;14(Suppl D):60D-6D.

35. Smith C, Gasparetto M, Jordan C, Pollyea DA, Vasiliou V. The effects of alcohol and aldehyde dehydrogenases on disorders of hematopoiesis. Adv Exp Med Biol. 2015;815:349-59.

36. Doi T, Homma H, Mezawa S, Kato J, Kogawa K, Sakamaki S, et al. Mechanisms for increment of platelet associated IgG and platelet surface $\operatorname{IgG}$ and their implications in immune thrombocytopenia associated with chronic viral liver disease. Hepatol Res. 2002;24(1):23.

37. Nagamine T, Ohtuka T, Takehara K, Arai T, Takagi H, Mori M. Thrombocytopenia associated with hepatitis $\mathrm{C}$ viral infection. J Hepatol. 1996;24(2):135-40.

38. Brouwer WP, Xie Q, Sonneveld MJ, Zhang N, Zhang Q, Tabak F, et al. Adding pegylated interferon to entecavir for hepatitis $\mathrm{B}$ e antigen-positive chronic hepatitis $\mathrm{B}$ : a multicenter randomized trial (ARES study). Hepatology. 2015;61(5):1512-22.

39. Peck-Radosavljevic M, Wichlas M, Homoncik-Kraml M, Kreil A, Hofer H, Jessner W, et al. Rapid suppression of hematopoiesis by standard or pegylated interferon-alpha. Gastroenterology. 2002;123(1):141-51.

40. Schmid M, Kreil A, Jessner W, Homoncik M, Datz C, Gangl A, et al. Suppression of haematopoiesis during therapy of chronic hepatitis $\mathrm{C}$ with different interferon alpha mono and combination therapy regimens. Gut. 2005;54(7):1014-20.

41. Peck-Radosavljevic M, Wichlas M, Pidlich J, Sims P, Meng G, Zacherl $\mathrm{J}$, et al. Blunted thrombopoietin response to interferon alfa-induced thrombocytopenia during treatment for hepatitis C. Hepatology. 1998;28(5):1424-9. 
42. Pereira J, Accatino L, Alfaro J, Brahm J, Hidalgo P, Mezzano D. Platelet autoantibodies in patients with chronic liver disease. Am J Hematol. 1995;50(3):173-8.

43. Kajihara M, Kato S, Okazaki Y, Kawakami Y, Ishii H, Ikeda Y, et al. A role of autoantibody-mediated platelet destruction in thrombocytopenia in patients with cirrhosis. Hepatology. 2003;37(6):1267-76.

44. Pradella P, Bonetto S, Turchetto S, Uxa L, Comar C, Zorat F, et al. Platelet production and destruction in liver cirrhosis. J Hepatol. 2011;54(5):894-900.

45. Olariu M, Olariu C, Olteanu D. Thrombocytopenia in chronic hepatitis C. J Gastrointestin Liver Dis. 2010;19(4):381-5.

46. Davis GL, Lau JY, Lim HL. Therapy for chronic hepatitis C. Gastroenterol Clin North Am. 1994;23(3):603-13.

47. Veldt BJ, Heathcote EJ, Wedemeyer H, Reichen J, Hofmann WP, Zeuzem S, et al. Sustained virologic response and clinical outcomes in patients with chronic hepatitis $\mathrm{C}$ and advanced fibrosis. Ann Intern Med. 2007;147(10):677-84.

48. Talal AH, LaFleur J, Hoop R, Pandya P, Martin P, Jacobson I, et al. Absolute and relative contraindications to pegylated-interferon or ribavirin in the US general patient population with chronic hepatitis C: results from a US database of over 45,000 HCV-infected, evaluated patients. Aliment Pharmacol Ther. 2013;37(4):473-81.

49. Maan R, van der Meer AJ, Hansen BE, Feld JJ, Wedemeyer H, Dufour JF, et al. Effect of thrombocytopenia on treatment tolerability and outcome in patients with chronic HCV infection and advanced hepatic fibrosis. J Hepatol. 2014;61(3):482-91.

50. Bourliere M. Peripheral blood cytopenia before treatment in HCV patients: is it a limitation for HCV treatment in the era of DAA? Liver Int. 2012;32(7):1033-6.

51. Curry MP, Forns X, Chung RT, Terrault NA, Brown R Jr, Fenkel $\mathrm{JM}$, et al. Sofosbuvir and ribavirin prevent recurrence of $\mathrm{HCV}$ infection after liver transplantation: an open-label study. Gastroenterology. 2015;148(1):100-7 e1.

52. Cobb WS, Heniford BT, Burns JM, Carbonell AM, Matthews $\mathrm{BD}$, Kercher KW. Cirrhosis is not a contraindication to laparoscopic surgery. Surg Endosc. 2005;19(3):418-23.

53. Wallace MJ, Narvios A, Lichtiger B, Ahrar K, Morello FA Jr, Gupta S, et al. Transjugular liver biopsy in patients with hematologic malignancy and severe thrombocytopenia. J Vasc Interv Radiol. 2003;14(3):323-7.

54. Seeff LB, Everson GT, Morgan TR, Curto TM, Lee WM, Ghany MG, et al. Complication rate of percutaneous liver biopsies among persons with advanced chronic liver disease in the HALTC trial. Clin Gastroenterol Hepatol. 2010;8(10):877-83.

55. Giannini EG, Greco A, Marenco S, Andorno E, Valente U, Savarino V. Incidence of bleeding following invasive procedures in patients with thrombocytopenia and advanced liver disease. Clin Gastroenterol Hepatol. 2010;8(10):899-902 (quiz e109).

56. Sharma M, Yong C, Majure D, Zellner C, Roberts JP, Bass NM, et al. Safety of cardiac catheterization in patients with end-stage liver disease awaiting liver transplantation. Am J Cardiol. 2009; 103(5):742-6.

57. Fillmore WJ, Leavitt BD, Arce K. Dental extraction in the thrombocytopenic patient is safe and complications are easily managed. J Oral Maxillofac Surg. 2013;71(10):1647-52.

58. Basser R. The impact of thrombopoietin on clinical practice. Curr Pharm Des. 2002;8(5):369-77.

59. Kuter DJ, Begley CG. Recombinant human thrombopoietin: basic biology and evaluation of clinical studies. Blood. 2002;100(10):3457-69.

60. Li J, Yang C, Xia Y, Bertino A, Glaspy J, Roberts M, et al. Thrombocytopenia caused by the development of antibodies to thrombopoietin. Blood. 2001;98(12):3241-8.
61. Solberg LA Jr. Biologic aspects of thrombopoietins and the development of therapeutic agents. Curr Hematol Rep. 2005;4(6):423-8.

62. Burness CB. Eltrombopag: a review of its use in the treatment of thrombocytopenia in patients with chronic hepatitis C. Drugs. 2014;74(16):1961-71.

63. McHutchison JG, Dusheiko G, Shiffman ML, Rodriguez-Torres M, Sigal S, Bourliere M, et al. Eltrombopag for thrombocytopenia in patients with cirrhosis associated with hepatitis C. N Engl J Med. 2007;357(22):2227-36.

64. Afdhal NH, Giannini EG, Tayyab G, Mohsin A, Lee JW, Andriulli A, et al. Eltrombopag before procedures in patients with cirrhosis and thrombocytopenia. $\mathrm{N}$ Engl J Med. 2012;367(8):716-24.

65. Afdhal NH, Dusheiko GM, Giannini EG, Chen PJ, Han KH, Mohsin A, et al. Eltrombopag increases platelet numbers in thrombocytopenic patients with HCV infection and cirrhosis, allowing for effective antiviral therapy. Gastroenterology. 2014;146(2):442-52 e1.

66. Fukushima-Shintani M, Suzuki K, Iwatsuki Y, Abe M, Sugasawa K, Hirayama F, et al. AKR-501 (YM477) in combination with thrombopoietin enhances human megakaryocytopoiesis. Exp Hematol. 2008;36(10):1337-42.

67. Fukushima-Shintani M, Suzuki K, Iwatsuki Y, Abe M, Sugasawa K, Hirayama F, et al. AKR-501 (YM477) a novel orally-active thrombopoietin receptor agonist. Eur J Haematol. 2009;82(4):247-54.

68. Terrault NA, Hassanein T, Howell CD, Joshi S, Lake J, Sher L, et al. Phase II study of avatrombopag in thrombocytopenic patients with cirrhosis undergoing an elective procedure. J Hepatol. 2014;61(6):1253-9.

69. Moussa MM, Mowafy N. Preoperative use of romiplostim in thrombocytopenic patients with chronic hepatitis $\mathrm{C}$ and liver cirrhosis. J Gastroenterol Hepatol. 2013;28(2):335-41.

70. Buccoliero G, Urbano T, Massa P, Resta F, Pisconti S. Romiplostim for severe thrombocytopenia in the treatment of chronic hepatitis $\mathrm{C}$ virus infection: a new option for clinicians? New Microbiol. 2014;37(1):97-101.

71. Taylor N, Melchardt T, Grundbichler M, Strasser M, Egle A, Greil R. Use of romiplostim allows for hepatitis C therapy in a HIV/HCV coinfected patient. Ann Hematol. 2013;92(7):1001-2.

72. Voican CS, Naveau S, Perlemuter G. Successful antiviral therapy for hepatitis $\mathrm{C}$ virus-induced cirrhosis after an increase in the platelet count with romiplostim: two case reports. Eur J Gastroenterol Hepatol. 2012;24(12):1455-8.

73. Castellote J, Girbau A, Arajol C, Xiol X. Romiplostim in chronic liver disease with severe thrombocytopenia undergoing an elective invasive procedure. Rev Esp Enferm Dig. 2011;103(10):556.

74. Dultz G, Kronenberger B, Azizi A, Mihm U, Vogl TJ, Sarrazin U, et al. Portal vein thrombosis as complication of romiplostim treatment in a cirrhotic patient with hepatitis $\mathrm{C}$-associated immune thrombocytopenic purpura. J Hepatol. 2011;55(1):229-32.

75. GlaxoSmithKline. PROMACTA ${ }^{\circledR}$ (eltrombopag) tablets: US prescribing information. 2015. Available from: http://www. accessdata.fda.gov/drugsatfda_docs/label/2015/022291s014lbl. pdf. Cited 11 May 2015.

76. GlaxoSmithKline. Revolade $25 \mathrm{mg}$ film-coated tablets: summary of product characteristics. 2015. Available from: http://www. ema.europa.eu/docs/en_GB/document_library/EPAR_-_Product_ Information/human/001110/WC500089964.pdf. Cited 11 May 2015.

77. Amgen. Nplate ${ }^{\circledR}$ (romiplostim) for subcutaneous injection: US prescribing information. 2014. Available from: http://www. accessdata.fda.gov/drugsatfda_docs/label/2014/125268s141lbl. pdf. Cited 11 May 2015. 
78. Amgen. Nplate 250 micrograms powder for solution for injection: summaryof product characteristics. 2015. Available from: http://www.ema.europa.eu/docs/en_GB/document_library/

EPAR_-_Product_Information/human/000942/WC500039537. pdf. Cited 11 May 2015.

79. Afdhal N, Reddy KR, Nelson DR, Lawitz E, Gordon SC, Schiff $\mathrm{E}$, et al. Ledipasvir and sofosbuvir for previously treated $\mathrm{HCV}$ genotype 1 infection. N Engl J Med. 2014;370(16):1483-93.
80. Poordad F, Hezode C, Trinh R, Kowdley KV, Zeuzem S, Agarwal $\mathrm{K}$, et al. ABT-450/r-ombitasvir and dasabuvir with ribavirin for hepatitis C with cirrhosis. N Engl J Med. 2014;370(21):1973-82.

81. Kowdley KV, Lawitz E, Crespo I, Hassanein T, Davis MN, DeMicco M, et al. Sofosbuvir with pegylated interferon alfa-2a and ribavirin for treatment-naive patients with hepatitis $\mathrm{C}$ genotype-1 infection (ATOMIC): an open-label, randomised, multicentre phase 2 trial. Lancet. 2013;381(9883):2100-7. 